\title{
Educação Científica e Ambiental através de diálogos e práticas no Museu de História Natural da Universidade Federal de Lavras
}

\section{Science Education and Environmental through dialogue and practices at the Natural History Museum of the Federal University of Lavras}

\author{
${ }^{1}$ José Sebastião Andrade de Melo \\ ${ }^{1}$ Lorrana Nascimento Ferreira \\ ${ }^{1}$ Antonio Fernandes Nascimento Júnior
}

\section{RESUMO}

O presente trabalho tem como objetivo fazer um estudo sobre as práticas e atividades que buscaram aproximar dialogicamente aspectos da Educação Científica e Ambiental no Museu de História Natural (MHN) da Universidade Federal de Lavras (UFLA). Com a análise de relatos de experiências publicados em periódicos ou anais de congressos, encontros ou simpósios nacionais intenciona-se identificar as tendências pedagógicas presentes neste espaço não formal de educação. Os relatos de experiência, analisados a partir de referencial bibliográfico específico, mostraram que o MHN aproximou diferentes temáticas científicas e ambientais fazendo isso através elementos pedagógicos de tendências construtivistas/cognitivistas, ora com elementos histórico-culturais ora com elementos críticos-sociais, além de integrar a elas processos voltados para a formação inicial de professores.

Palavras-chave: Educação Científica e Ambiental, Educação Não Formal, Formação de Professores.

\section{ABSTRACT}

This paper aims to make a study of the practices and activities that sought closer dialogical aspects of Scientific and Environmental Education at the Natural History Museum (MHN) of the University Federal of Lavras (UFLA). With analysis experience reports published in journals or conference proceedings, meetings and national symposia, the intend is to identify the pedagogical present trends in this non-formal education space. The experience reports, analyzed from specific bibliographic references showed that the MHN approached various scientific and environmental issues doing this through pedagogical elements of constructivist tendencies / cognitive, sometimes with historical and cultural elements sometimes with critical - social elements, and do it integrating the process teacher training.

Keywords: Scientific and Environmental Education, Non-Formal Education, Teacher Training.

(Apoio: FAPEMIG e CAPES) 


\section{INTRODUÇÃO}

Pensar e realizar práticas voltadas para a educação científica e para educação ambiental configura-se um dos importantes desafios para educadores brasileiros. O desafio ainda é maior quando a intenção é aproximar essas duas áreas. O caminho para superá-lo deve partir do pressuposto que a compreensão do mundo é constituída por narrativas e que a ciência é um exemplo destas narrativas que tenta explicar, essencialmente, a natureza e seus fenômenos. Nessa perspectiva as diferentes ciências naturais estão indissociavelmente integradas ao meio ambiente. Todavia esta relação de integração, por inúmeros fatores do cotidiano da educação básica, mesmo estando presente nos documentos oficiais que definem as diretrizes curriculares (BRASIL, 1996; BRASIL 1999; MINAS GERAIS, 2007), muitas vezes não é devidamente explicitada na sala de aula. É possível destacar dentre os fatores que dificultam a aproximação dos conteúdos científicos da temática ambiental nos espaços formais de educação, a pequena carga horária das disciplinas de ciências, a escassez de recursos didáticos não meramente expositivos e a impossibilidade ou dificuldade de realização de atividades inter e transdisciplinares que juntos resultam na ausência de momentos para o debate que correlacionem temas científicos e ambientais.

Com a existência e permanência de tais obstáculos na educação formal, mas não devido somente a isto, outros ambientes educativos classificados como espaços não formais de educação passaram a contribuir com o importante papel da realização e disseminação de práticas que relacionam a educação científica com a educação ambiental. Fato este que segundo Jacobucci (2008) vem ocorrendo ao longo das últimas décadas em nosso país onde os centros e museus de ciências tem buscado superar as dificuldades existentes nas escolas através de suas exposições, da atuação de seus educadores e por meio da proposição de atividades inovadoras, criativas e intersdisciplinares que ainda buscam contribuir para a formação inicial e continuada de professores.

\section{OBJETIVOS}

O presente trabalho tem como objetivo fazer um estudo sobre as práticas e atividades que buscaram aproximar dialogicamente aspectos da Educação Científica e Ambiental no Museu de História Natural (MHN) da Universidade Federal de Lavras (UFLA). Com este estudo intenciona-se identificar as tendências pedagógicas presentes neste espaço não formal de educação.

\section{METODOLOGIA}

A metodologia adotada neste estudo consiste na análise, a partir de referenciais bibliográficos específicos, de práticas e atividades realizadas no Museu de História Natural da UFLA que buscaram construir um diálogo nas áreas da educação científica e da educação ambiental e que deram origem a relatos de experiências publicados em periódicos ou anais de congressos, encontros ou simpósios nacionais. Para facilitar a identificação de aspectos relevantes que puderam esboçar a pedagogia museal presente neste espaço de educação não formal, as práticas pesquisadas foram categorizadas em três grupos distintos, a saber: práticas voltadas para formação de professores (PVFP); práticas propositivas de estratégias pedagógicas (PPEP); e oficinas educativas (OE).

\section{RESULTADOS E DISCUSSÃO TEÓRICA}

O espaço da escola vem sendo alvo de inúmeros questionamentos a respeito do seu histórico papel de centralidade na promoção do letramento da sociedade. Quando nos reportamos ao cenário da pesquisa em Educação em Ciências, percebemos vários relatos que apontam uma ampliação das possibilidades de espaços formativos, a exemplo dos Museus e Centros de Ciências, onde é possível aprender e ensinar (JACOBBUCCI, 2008). 
Nesse contexto por meio de práticas empreendidas no Museu de História Natural (MHN) da Universidade Federal de Lavras (UFLA) buscou-se ampliar as possibilidades formativas dos licenciandos, tradicionalmente voltadas para atuação escolar e, além disso, promover a integração de ações nos âmbitos da educação científica e ambiental em um espaço não formal de educação.

Diversos autores reconhecem que os museus, os centros de ciência e outros espaços de educação não formal, nas últimas décadas têm assumido um papel de destaque para viabilização de práticas que fomentem a popularização da ciência assim como a formação inicial e continuada de professores (LAYTON 1986; GOUVÊA e LEAL, 2000; MARANDINO et al., 2003; MELO et al., 2008). Diante deste quadro apresentaremos o relato de algumas iniciativas desenvolvidas na Universidade Federal de Lavras, por meio de um programa e um projeto, respectivamente denominados, Programa Institucional de Bolsas de Iniciação à Docência em Biologia (PIBIDBiologia/UFLA) e Projeto Novos Olhares para o Museu de História Natural da UFLA. Tais iniciativas foram planejadas, elaboradas e executadas por pesquisadores e por alunos dos cursos das Licenciaturas da UFLA e colocadas em práticas no MHN.

\section{1 Relato de algumas práticas realizadas no Museu de História Natural da UFLA voltadas especifica- mente para formação inicial de professores}

Melo et al. (2014) apresenta uma ação do projeto Novos olhares para o Museu de História Natural da UFLA realizada no próprio MHN que trouxe contribuições para a formação inicial de professores de química. Os autores investigaram o desenvolvimento de uma proposta didática que explorava o acervo de mineralogia deste museu. Como resultado os professores em formação desenvolveram a prática pedagógica intitulada "Detetives no Museu - Investigando a questão de que é feito nosso planeta?” e a utilizaram com grupos de públicos escolares que agendaram participação na prática. Com ela houve confirmação da hipótese levantada pelos autores quanto às contribuições para a formação inicial dos futuros professores envolvidos, tendo em vista que a participação deles no planejamento e na execução da prática pedagógica em um museu de ciências possibilitou a oportunidade de complementarem sua formação explorando um espaço não formal de ensino, o que ainda hoje é pouco usual nos cursos de licenciatura.

Uma segunda ação que revelou possibilidades para a formação inicial de professores no MHN foi a aproximação ocorrida nos últimos anos entre este museu e o Programa Institucional de Bolsas de Iniciação à Docência em Biologia da UFLA, envolvendo ainda seis escolas públicas de Lavras MG. O primeiro tema escolhido para ser trabalhado neste programam foi Bioma, por ser considerado um tema gerador no ensino de Ciências e Biologia. Além disso, Andrade e Nascimento Júnior (2014) também relatam que a partir do conceito de Bioma foi possível abranger uma grande gama de conteúdos que puderam ser bem trabalhados de acordo com o acervo e as exposições do MHN. Os estudos sobre a formação de professores indicam como sendo essencial à formação de professores o desempenho de atividades teórico-práticas. Libâneo e Pimenta (1999) sugerem ainda que não há como pensar na possibilidade de educar se situando fora de casos reais e concretos; portanto uma formação completa deve combinar de maneira proporcional a teoria à prática. As atividades realizadas no MHN em parceria com o PIBID-Biolofia/ UFLA têm atendido a essa preocupação, realizando seminários de formação e ainda executando as atividades.

\section{2 As práticas propositivas de estratégias pedagógicas utilizadas no MHN}

O MHN tem se apresentado como um espaço integrador, o que contribui significativamente para a melhoria da educação científica de Lavras e região e ainda para a formação de professores que atuam em práticas voltadas para a educação ambiental. Mas não é apenas o contato com o espaço do Museu de História Natural que possibilita o licenciando enxergar o potencial daquele espaço como promotor de processos de ensino aprendizagem. O contato foi apenas um primeiro passo de uma jornada que se revelou formativa e que se propôs construtivista. A presença de sujeitos em formação inicial neste espaço não formal de educação como veremos a seguir, possibilitou a visualização e construção de novas práticas de ensino. 
Dentre as práticas que classificamos como sendo propositivas de estratégias pedagógicas destacaram-se aquelas que utilizaram o recurso do cinema. Nas dependências do MHN houve uma mostra de cinema com temática estritamente relacionada à ciência. Denominada "História da Ciência no Cinema" essa mostra teve o intuito de convidar a comunidade para discutir aspectos socioeconômicos do desenvolvimento da ciência. Tendo entendimento e consciência do grande potencial cognitivo dos filmes que trazem a discussão da ciência para as telas (ex.: biografias dos cientistas e construções de narrativas científicas), nesta prática as apresentações aconteceram dentro de uma dimensão crítica, formativa e pedagógica. No total foram exibidas cinco obras cinematográficas, foram elas: Contato (Dir. Robert Zemeckis, 1997); O ponto de Mutação (Dir. Bernt Amadeus Capra, 1990); O nome da Rosa (Dir. Jean Jacques Annaud, 1986) Galileo (Dir. Joseph Losey, 1975); Giordano Bruno (Dir. Giuliano Montaldo, 1973). Dentre os resultados obtidos após as experiências relatadas e após o estudo destes filmes destacaram-se os seguintes: (i) foi enriquecedora a experiência de integração do espaço museal com o cinema, assim como; (ii) foi válido trabalhar a temática científica através do cinema, sendo que; e (iii) os filmes analisados consistem em um excelente material didático, tanto para enriquecer a formação dos espectadores, por promoverem a veiculação e a divulgação científica, quanto para a análise do pensamento científico, como também para compreensão da história da ciência.

Outra prática propositiva de estratégia pedagógica realizada no MHN foi relatada por Andrade et al. (2014) onde os autores apresentam e discutem a utilização do teatro de máscaras como uma estratégia lúdica para o ensino de ciências e biologia. Como material didático pedagógico utilizado confeccionou-se máscaras representando faces de animais com os objetivos específicos de difundir conhecimentos sobre a fauna regional e de ensinar de ecologia através de representações teatrais. Com o teatro de máscaras foi possível introduzir conteúdos ecológicos e comportamentais de animais típicos da nossa região e a peça trazia o título "Na natureza a vida funciona mais ou menos assim”. O roteiro foi uma adaptação do texto extraído do livro em CD-ROM intitulado "Máscaras da fauna brasileira: Faces para o ensino e divulgação da ecologia, etologia, zoologia e educação ambiental” de autoria Souza e Nascimento Júnior (2010). Um aspecto relevante a ser evidenciado foi que a ludicidade do teatro como forma de ensinar conceitos biológicos mostrou-se bastante eficaz e provocou encantamento aos alunos, que por sua vez, interessaram em aprender a partir dessa estratégia.

Compartilhando a ideia que as concepções tradicionais de ensino reforçam o sentido prático-utilitário dos saberes, Cortez et al. (2013) com as proposições de atividades de trilhas no MHN buscaram atuar de forma a superar tais concepções. Para que os participantes destas atividades percebessem a relação do ser humano com a natureza, a opção foi desenvolver as trilhas num ambiente antropizado, concordando com Bruhns (2010) que critica o mito da natureza intocada, como nas viagens contemporâneas, onde o ser humano é sempre um visitante e nunca um morador. Após a realização da trilha em torno do MHN houve a mediação dos bolsistas, licenciandos do curso de Biologia, para a construção dos conceitos através de um jogo pedagógico de memória, que buscava construir os conceitos de habitat e nicho ecológico. Posteriormente ocorria a visita guiada ao acervo do museu para entendê-los num contexto micro para o macro ecológico.

\section{3 As oficinas educativas (OE) realizadas no Museu de História Natural}

Oliveira, et al. (2014) apresenta uma proposta de oficina pedagógica de educação ambiental focada na reutilização de materiais que estimulou os participantes a elaborarem uma abordagem crítica do tema. A oficina consistiu, inicialmente, de discussões acerca dos problemas ambientais relacionados à produção e descarte indevido de lixo, além do consumismo. A discussão buscou tratar ainda dos impactos causados pelo lixo à vida das pessoas, sejam eles diretamente ligados aos seres humanos, à saúde pública, à biodiversidade ou até mesmo às relações que os seres humanos têm com a natureza em geral, principalmente no que diz respeito às interações com o ambiente e os recursos naturais como um todo. Para subsidiar as discussões, os mediadores atuando no MHN exibiram imagens que mostravam o descarte desenfreado de lixo e um pequeno vídeo, A História das Coisas (Dir. Louis Fox, 2005), que trata dos processos pelos quais os produtos passam durante o ciclo de produção. A atividade contou ainda com a elaboração de dois teatros de fantoches, produzidos através de materiais reutilizáveis. 
Também foram realizadas oficinas educativas que exploraram a possibilidade de se trabalhar conceitos relacionados ao ensino de ecossistemas terrestres como tema gerador para práticas de educação ambiental, foi usado para tal o recurso da construção de terrários. Segundo Paula et al. (2013) os resultados indicaram que a utilização do terrário na formação de professores se mostrou uma ferramenta com grande potencial, configurando modelos de processos de ensino-aprendizagem em ecologia por favorecer a visualização de vários aspectos conceituais relacionados com conteúdos presentes nas propostas curriculares e no cotidiano dos estudantes.

\title{
4. 4 As tendências pedagógicas presentes nas práticas do MHN
}

Hoje no MHN convivem os três tipos de práticas categorizadas anteriormente. As práticas voltadas para formação de professores (PVFP) têm suas concepções norteadas por características como: viabilizar a interação direta do licenciando com o espaço do museu, preferencialmente de forma construtivista/cognitivista, que segundo Cazelli (1999):

\begin{abstract}
são centradas nos processos de ensino-aprendizagem, as abordagens que resgatam a dimensão social procurando vincular o ensino de ciências com a ideia de escola como fator importante na transformação social e a abordagem histórica e filosófica da ciência. (Cazelli,1999, p. 3)
\end{abstract}

Nas práticas propositivas de estratégias pedagógicas (PPEP) é possível identificar uma aproximação das tendências pedagógicas construtivistas/cognitivistas com conteúdos históricos culturais. Nestas práticas delinearam-se ligações entre ciência, vida social, política, e arte. Para isso foram utilizados variados recursos pedagógicos, trazendo a temática do cinema, do teatro, dos jogos e da trilha ecológica. O conjunto possibilitou uma narrativa que articula mudanças nas visões de mundo, nas práticas educativas e cotidianas.

As oficinas educativas (OE) realizadas no MHN procuraram atender à multidimensionalidade do processo educativo. A tendência pedagógica presente nestas oficinas foi de caráter progressista crítico-social dos conteúdos. Segundo Libâneo (1994) tal tendência traz os conteúdos para o cerne da discussão, reavaliando-os continuamente face ao contexto sociocultural dos estudantes. Esta tendência pedagógica tem na democratização dos conhecimentos a principal tarefa dos espaços educativos na nossa sociedade, garantindo desse modo uma cultura de base para que professores e estudantes possam utilizá-la no seu cotidiano. Durante as oficinas realizadas no MHN as experiências da vida do público foram levadas em conta desde o início do processo de ensino-aprendizagem. Os prelecionistas buscaram conhecer este cotidiano, e a partir deste conhecimento, ajudar o público a ultrapassar seus saberes por meio do desenvolvimento do senso crítico e da apresentação de conteúdos novos que resultaram em uma nova forma de elaboração, possibilitando assim provavelmente em uma transformação de todos os envolvidos.

\section{CONCLUSÕES}

Através de uma pedagogia museal progressista e crítica, as práticas e atividades do Museu de História Natural da Universidade Federal de Lavras operam nos âmbitos da educação científica e ambiental. Os relatos de experiência analisados neste estudo mostraram que o MHN aproximou diferentes temáticas científicas e ambientais, fazendo isso através elementos pedagógicos de tendências construtivistas/cognitivistas, ora com elementos histórico-culturais ora com elementos críticos-sociais, além de integrar a elas processos voltados para a formação de professores. Os relatos também mostraram que as práticas foram importantes na construção da consciência crítica da educação ambiental, despertando a noção de que o ser humano pertence ao meio ambiente e que através do conhecimento científico atua diretamente na sua transformação. A estruturação do espaço do museu pode ser organizada de acordo com o objetivo a ser alcançado em cada prática ou atividade, assim as diferentes metodologias puderam também se adaptar ao acervo do museu, aproveitando o que o mesmo tinha a oferecer para os públicos envolvidos.

Finalizando, é possível afirmar concordando com Andrade e Nascimento Júnior (2014) que novas práticas de ensino são muito importantes para mudar o cenário da educação atual, e que práticas formativas contribuem significativamente para que haja tal mudança. 


\section{REFERÊNCIAS BIBLIOGRÁFICAS}

ANDRADE, A. L. S.; SILVA, T.; NASCIMENTO JÚNIOR, A. F. O lúdico como estratégia pedagógica: o teatro de máscaras para o ensino de ciências/biologia pelo PIBID de biologia da Universidade Federal de Lavras MG. Revista da Associação Brasileira de Ensino de Biologia (SBEnBio), v. 7, p. 617-623, 2014.

ANDRADE, M. N. B. ; NASCIMENTO JÚNIOR, A. F. . Uma parceria entre museu, PIBID e escolas na formação inicial de professores de ciências e biologia da Universidade Federal de Lavras MG. Revista da Associação Brasileira de Ensino de Biologia (SBEnBio), v. 7, p. 5618-5629, 2014.

BRASIL, Ministério da Educação, Secretaria de Educação Média e Tecnológica. Parâmetros Curriculares Nacionais: Ensino Médio. Brasília: MEC, 1999, 364p.

BRASIL. Lei no 9394, de 20 de dezembro de 1996. Estabelece as Diretrizes e Bases da Educação Nacional. Brasília, Disponível em: <http://www.planalto.gov.br/ccivil_03/ leis/19394.htm>. Acesso em: 04 abr. 2015.

BRUHNS, H. O ecoturismo e mito da natureza intocada. Acta Scientiarum. Human and Social Science, v. 60, p. 157-164, 2010.

CAZELLI, S. ; QUEIROZ, G. ; ALVES, F. ; FALCÃO, D. ; VALENTE, M. E. ; GOUVÊA, G. ; COLINVAUX, D. . Tendências pedagógicas das exposições de um museu de ciência. In: II Encontro Nacional de Pesquisa em Educação em Ciências - ENPEC, 1999, Valinhos - São Paulo. Resumos do II ENPEC, p 1-12, 1999.

CORTEZ, M. T. J. ; PACHECO, G. S. M. ; ANDRADE, M. N. B. ; NASCIMENTO JÚNIOR, A. F.. A trilha e a formação de professores: tecendo caminhos para a educação ambiental. In: I Encontro de Biologia, 2013, Muzambinho. Anais do I Encontro de Biologia, p. 1-1, 2013.

GOUVÊA, G e LEAL, M. C. Narrativa, mito, ciência e tecnologia: o ensino de ciências na escola e no museu. Revista Ensaio Pesquisa Em Educação Em Ciências, Belo Horizonte, v. 1, n. 2, p. 5-36, 2000.

JACOBUCCI, D. F. C. Contribuições dos espaços não-formais de educação para a formação da cultura científica. Em Extensão, v. 7, n. 1, p. 55-66, 2008.

LAYTON D Science for Specific Social Purposes (SSSP): Perspectives on Adult Scientific Literacy. Studies in Science Education, v13 p27-52, 1986.

LIBÂNEO, J. C. e PIMENTA, S. G. Formação de profissionais da educação: visão crítica e perspectiva de mudança. Educação \& Sociedade, v. 20, n. 68, p. 239-277, 1999

LIBÂNEO, J.C. Didática. São Paulo: Cortez. 1994.

MARANDINO, M.; SILVEIRA, R. V. M. da; CHELINI, M. J.; FERNANDES, A. B.; RACHID, V. MARTINS, C.; LOURENÇO, M. F.; FERNANDES, J. A. e FLORENTINO, H. A. A educação não-formal e a divulgação científica: O que pensa quem faz? In: IV Encontro Nacional de Pesquisa em Ensino De Ciências, n.4, 2003, Bauru. Livro de resumos - IV ENPEC. Bauru: ABRAPEC, p. 1-12, 2003.

MELO, J. S. A.; MONTEIRO, B. A. P.; CARVALHO, F. C.; PINTO, L. de M. A.; SOARES, A. M.. O Museu de História Natural da UFLA como espaço de Divulgação Científica e a Formação Inicial de Professores. Revista Extendere, v. 2, p. 149-165, 2014.

MELO, J. S. A. de; VIANA, E. C.; FRANÇA, F. M. e MONTEIRO, B. A. P. Ensino de Ciências em espaços não formais de educação: Despertando o interesse de adolescentes pelas ciências. In: XXII Encontro Regional da Sociedade Brasileira de Química de Minas Gerais.2008, Belo Horizonte. Resumos - XXII Encontro regional da SBQ/MG. p. 1-2 2008. 
MINAS GERAIS. Conteúdo Básico Comum (CBC). Proposta Curricular: Ciências, Ensino Fundamental. Secretaria de Estado de Educação de Minas Gerais, 2007.

OLIVEIRA, L. A.; SILVA, A. M.; NASCIMENTO JÚNIOR, A. F. Oficina de reutilização de materiais: educação ambiental crítica na formação de professores. Fórum Ambiental da Alta Paulista, v. 10, p. 46-57, 2014.

PAULA, J. R. B.; SILVA, M. P.; NASCIMENTO JÚNIOR, A. F. Utilização do terrário em um minicurso de formação inicial de professores como modelo para o ensino da ecologia. In: I Encontro de Biologia, 2013, Muzambinho. Anais do I Encontro de Biologia, p.1-1, 2013.

SOUZA, D. C. de; NASCIMENTO JÚNIOR, A. F. Máscaras da Fauna Brasileira: Faces para o ensino e divulgação da Ecologia, Etologia, Zoologia e Educação Ambiental. Brasília: Sociedade dos Zoológicos do Brasil, 2010. CD-ROM. 